\title{
APPLYING A MULTI-SERVICE DIGITAL DISPLACEMENT® PUMP TO AN EXCAVATOR TO REDUCE VALVE LOSSES
}

\author{
Matteo Pellegri*, Matthew Green, Jill Macpherson, Callan McKay, Niall Caldwell \\ Artemis Intelligent Power Limited, Unit 3, Edgefield Industrial Estate, Loanhead,EH20 9TB, United Kingdom \\ * Corresponding - author: Tel.: +44 (0)131440 6268; E-mail address: m.pellegri@artemisip.com
}

\begin{abstract}
Reducing the energy consumption of off-highway machinery due to poor system efficiency is an urgent challenge. Several advanced and innovative architectures have been proposed over the years to tackle this problem, but very few of them found fertile ground for commercial applications due to increased complexity and cost. In this paper, the design, implementation, and testing of a multi-service Digital Displacement ${ }^{\circledR}$ Pump architecture applied to an excavator are presented. The Digital Displacement $\mathbb{}$ Pump allows for a dynamic physical displacement allocation to services at different pressure levels, thus reducing throttling losses required to operate multiple actuators simultaneously. A feed-forward control logic is implemented and applied to the system using a closed-centre architecture. The results indicate a fuel reduction of more than $30 \%$ compared to the baseline excavator.
\end{abstract}

Keywords: Digital Displacement ${ }^{\circledR}$, Digital, Pumps, Excavator, Hydraulics

\section{INTRODUCTION}

As climate change accelerates, the inefficient energy usage of hydraulic off-highway machinery becomes a matter of global importance. Official estimates are that fluid power systems consume $2-3 \%$ of the USA's total energy [1], while estimates of typical hydraulic system efficiency range from $21 \%$ [1] to $30-50 \%$ [2]. The main reasons for this low efficiency are excessive dissipation in control valves, poor pump/motor efficiency, sub-optimal engine utilisation, and lack of recovery of kinetic and potential energy [3].

In previous work [4], the authors investigated the effect on an excavator of swapping the analog axial-piston pumps for Digital Displacement ${ }^{\circledR}$ pumps, thereby reducing the pump energy losses from $10.4 \mathrm{~kW}$ to $3.6 \mathrm{~kW}$ for a digging cycle, reducing the fuel consumption per cycle by $21.2 \%$ while increasing productivity by $10.4 \%$.

This work showed a substantial improvement for a relatively simple change to the system, and is now being commercialised [5]. However there is limited further potential of this approach, as the DDP pump losses $(3.6 \mathrm{~kW})$ are such a small fraction of the dominant valve throttling losses $(19.3 \mathrm{~kW})$, which cannot be significantly improved without changing the system architecture.
Ultimately, throttling losses may be avoided by eliminating proportional valves completely, and instead digitally connecting multiple displacement-controlled DDP pump outlets directly to the actuators [6]. Other authors have also investigated unconventional architectures to reduce throttling losses, such as displacement controlled (DC) circuits [7,2], independentmetering systems and decentralized electrohydraulics [8,9], 2-pressure level hybrid systems such as STEAM [10], and multi-chamber linear actuators [2].

The efficiency advantages of these approaches are in general counter-balanced by increased complexity and cost, uncertainty over safety, and reduced operator controllability. Vehicle manufacturers have typically taken a more evolutionary approach.

This work describes an evolutionary system which significantly reduces the throttling losses while preserving the same overall system architecture, safety and operator control characteristics.

The concept is demonstrated on a 16-ton excavator, by installing a 'multi-service' DDP, a switching valve block and associated system controllers. The original Negative-Flow (Negacon) control system is replaced by a closedcentre feed-forward control architecture in which 
the boom and bucket actuators are decoupled from the arm and swing, thus allowing each group of functions to work at a different pressure level. In this paper, the control system, test method, data analysis, and results are described.

\section{SYSTEM DESCRIPTION}

\subsection{DEXTER: The Digital-Displacement $₫$ Excavator}

\section{The Digital-Displacement $₫$ Pump (DDP)}

The Digital-Displacement ${ }^{\circledR}$ Pump (Figure 1) is a radial piston machine which enables and disables cylinders in real-time, using ultra-fast mechatronic valves controlled by an embedded computer. The advantages of DDP over traditional swash-plate pumps are mainly [11]:

1. Increased part-load efficiency due to the principle of displacement control by disabling cylinders

2. Faster response (typically less than $30 \mathrm{~ms}$ )

3. Lower high-frequency noise



Figure 1: Tandem configuration of a DigitalDisplacement ${ }^{\circledR}$ Pump 'E-dyn 96'

The pump installed on the excavator is a tandem configuration of an 'E-dyn 96'. The E-dyn 96 has $12 \times 8 \mathrm{cc}$ cylinders. The output of these cylinders can be combined to form one $96 \mathrm{cc} / \mathrm{rev}$ output, or multiple smaller outputs (for example $4 \mathrm{x}$ $24 \mathrm{cc} / \mathrm{rev}$ ), each output being independently controllable. In the tandem configuration used, the DDP has a total of $8 \times 24 \mathrm{cc} / \mathrm{rev}$ outputs, which are referred to as "Pumplets".

\section{The DEXTER hydraulic system}

The target machine is a JCB JS160, a 16 tonne tracked excavator property of Artemis Intelligent Power Limited. The specifications of the machine are summarized in Table 1. During the 'DEXTER' project, the axial piston pumps were replaced with a tandem E-dyn 96 DDP with two $96 \mathrm{cc} / \mathrm{rev}$ outputs [4]. The combination of the DDP and standard Negative-Flow control system that was developed during the DEXTER project will be referred to as 'System Architecture 1' (SA1).

Table 1: DEXTER Excavator (JCB JS160) Specifications

\begin{tabular}{ll}
\hline Machine parameter & Value \\
\hline Operating weight $[\mathrm{kg}]$ & 17774 \\
Engine Max Power $[\mathrm{kW}]$ & 93 \\
System Max Pressure [bar] & 343 \\
Pump Displacement [cc/rev] & $2 \times 96$ \\
\hline
\end{tabular}

\subsection{Concept of the 'Elastic Pump'}

In a traditional 2 pump negative flow control system like the JS160, the displacement of each pump is determined by the pressure across the 'Negacon' orifice, which is in series with the spool valve open centres. The boom and bucket functions are primarily serviced by Pump 1, while the arm and swing functions are primarily serviced by Pump 2. This allows two independent pressure levels, reducing the losses due to throttling compared to single pump systems. However, when the boom or arm functions require high flow, the flow from a single pump is insufficient, and the outputs of Pump 1 and 2 are combined via secondary spool valves. This results in a single flow source and therefore a single pressure level - and more throttling losses when multiple functions are operating.

In previous work [4], the authors measured the energy flow through the DEXTER SA1 system. The efficiency when grading was around $30 \%$. As shown in Figure 2 the most significant losses are due to throttling (shown as 'system losses'). Of these, $70 \%$ are associated to delivery and exhaust losses in the arm function. 




Figure 2: Losses in the grading cycle.

Much of the valve throttling losses for both digging and grading were found to be generated during periods of high flow of either boom or arm functions, when both Pump 1 and 2 were combined and operated at the highest pressure required by any actuator.

By working back from the actuator pressures, it was possible to calculate what the Pump 1 and Pump 2 pressures and flows would be if they were never combined in the valve block. The average mechanical power drawn from the engine could was determined to be $17.5 \%$ less (see Figure 3).

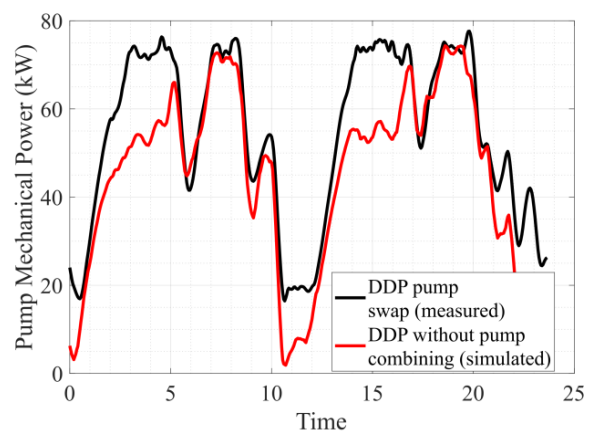

Figure 3: Simulation of effect of inhibiting pump combining

Of course the reason for the pumps combining is that the flow from a single pump is sometimes insufficient, so simply inhibiting the combining function would result in much lower productivity unless pump capacity was increased - which would significantly increase cost, space requirements and pump losses.

It was realised that the total pump capacity installed would not need to be increased if the apportionment of that capacity to each of Pump 1 and Pump 2 could be varied over the course of the duty cycle. Such a conceptual pump was termed "Elastic" because the capacity of each fluid supply could be stretched or shrunk as required.

\subsection{The 'Elastic Pump' System}

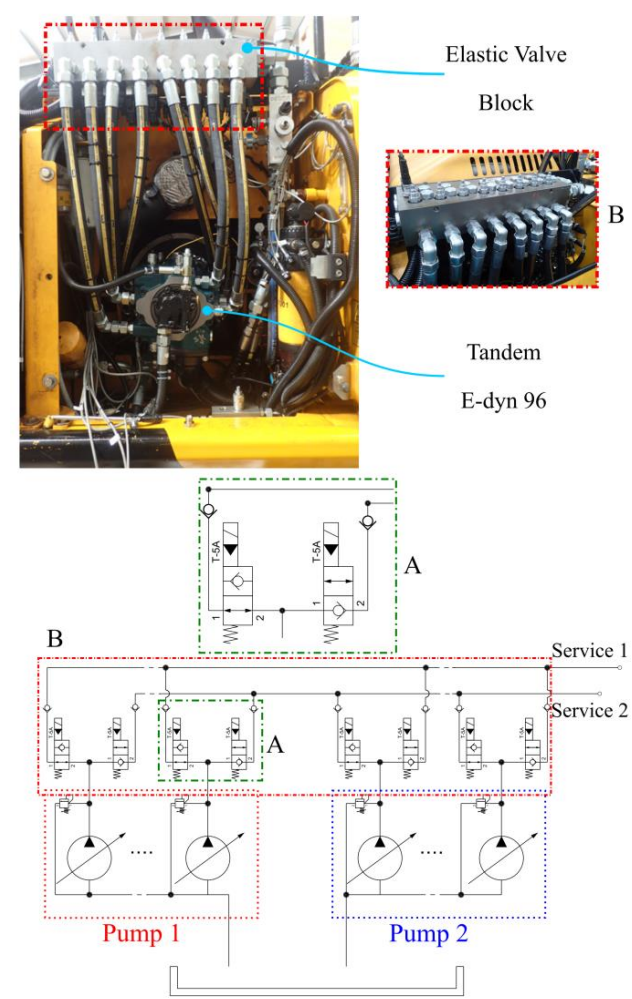

Figure 4: Physical implementation and schematic of the Elastic Pump System. The schematic shows the connection between the Pumplets and the two services using $2 / 2$ directional poppet valves working in parallel (detail A). There are four Pumplets per Pump, but only two are shown above for clarity.

Each 'Pumplet' of the 'E-dyn 96' can be controlled as a single variable displacement unit of $24 \mathrm{cc} / \mathrm{rev}$ or combined to obtain fractions of a tandem unit of $192 \mathrm{cc} / \mathrm{rev}$. For the current study, considering that the original circuit of the excavator has two pressure lines, the Pumplets can be combined to obtain two separate units of different possible sizes. A few examples, other than the obvious $96 / 96 \mathrm{cc} / \mathrm{rev}$, could be a $48 / 144$ $\mathrm{cc} / \mathrm{rev}$ or $0 / 192 \mathrm{cc} / \mathrm{rev}$ configurations. 
The flow redistribution to the two services is obtained using a valve block comprising $16 \times 2 / 2$ solenoid-operated directional poppet valves, 8 normally open and 8 normally closed as shown in Figure 4. This valve block will be referred to as the 'elastic valve block'.

Each Pumplet is connected to both services using one normally-open valve and one normally-closed: in the normal configuration 4 Pumplets are delivering flow to service 1 and 4 to service 2. When a change of pump 'size' is requested, both valves connected to a single Pumplet are activated and the flow is diverted to the desired service. This operation happens in synergy with the pump controller which now will have bigger and smaller physical displacements available for the two pumps with respect to the previous state.

The combination of the DDP and the Elastic Valve Block will be referred to as the Elastic Pump System, and also 'System Architecture 2'.

\section{Simulation model}

In order to verify the feasibility and worthiness of the new architecture, a backwards-facing simulation model aiming at quantifying the benefits in terms of potential fuel savings has been developed. This extends the previous model developed during the 'DEXTER' project [4], which was validated against experimental results. The model takes as inputs measured data of the original system and simulates what the fuel consumption would be with the modified system.

The flows the pumps need to provide are calculated from the ideal active flows requested by the actuators. Assuming a unitary efficiency for the linear actuators the flow required is calculated as

$Q_{l a}=v \cdot A$

For the hydraulic motors (e.g. swing motor) the required flow is calculated as

$Q_{m}=V_{d_{m}} \cdot \omega+Q_{\text {loss }}$

The volumetric losses for the hydraulic motors are calculated using the 'Polymod' approach described in [12], in which the losses are estimated using a polynomial fitting of experimental data together with scaling factors for different sized machines.

The flows are then combined to obtain the total flow associated with each service as follows
$Q_{s 1}=Q_{\text {boom }}+Q_{\text {bucket }}+Q_{\text {rtrack }}$

$Q_{s 2}=Q_{\text {swing }}+Q_{\text {arm }}+Q_{\text {ltrack }}$

The mechanical power required by the DDP to satisfy the total flow is calculated using a backward-facing simulation model described in [13] in which pressures, speed, and flows are fed as input and the fraction of displacement required to satisfy the flow request, fluid and mechanical power are the output. The volumetric displacement of the two pumps varies dynamically as described in the previous section and is calculated as

$V_{d_{S}}=\operatorname{ceil}\left(\frac{Q_{s}}{\frac{n}{1000}} \cdot \frac{1}{24}\right) \cdot 24$

with $V_{d}$ in cc/rev, $Q_{s}$ in $\mathrm{L} / \mathrm{min}$ and $n$ in rpm. In this way, the flow will be always satisfied even if the total size of the machine is greater than $192 \mathrm{cc} / \mathrm{rev}$. It has to be clarified that even though the machine size can be greater than $192 \mathrm{cc} / \mathrm{rev}$, the actual flow will be at most $192 \mathrm{cc} / \mathrm{rev}$ due to the fraction of displacement $F_{d s} \cdot V_{d s}$. To take into account the losses generated by non-working Pumplets the volumetric displacement of the idling portion of the DDP is simply calculated as

$V_{d_{\text {idle }}}=V_{d_{s 1}} \cdot\left(1-F_{d_{s 1}}\right)+V_{d_{s 2}} \cdot(1-$ $\left.F_{d_{s 2}}\right)$

The pressure for each service is defined by the function at the highest pressure.

Once the mechanical power is calculated for the tandem pump, the total torque is passed to an engine model containing the BSFC map of the engine. In this way, an accurate estimation of fuel consumption can be made.

The simulation model showed good potential for fuel savings with the new architecture. The simulation results are presented together with the experimental results in the results section.

\subsection{Modification to the DEXTER Hydraulic System}

As previously described, in the original Negacon system, the boom and bucket actuators are connected primarily to Pump 1, whilst arm and swing primarily to Pump 2. To minimise the number of modifications to the system, the original layout has been maintained. The communication between boom and arm and Service 2 and 1 respectively is prevented by blocking the secondary control valves. In the 
standard system, this would imply that the boom and the arm can now access only up to $96 \mathrm{cc} / \mathrm{rev}$. This problem can be tackled by the service switching capability of the DDP.

\section{Secondary directional control valves replacement}

The concept just presented allows for a complete separation of the two pressure lines allowing each actuator to be fed by a single service whilst satisfying the flow requirements. Modifications are required on the original hydraulic layout for the new control and hydraulic structures to work as intended.

First of all, as the Negacon pressure signal is not required, the Negacon lines can be blocked by turning the open-center system into a closedcenter one using solenoid-operated $2 / 2$ discrete position valves.

Secondly, the secondary valves which allow arm and boom to access Pump 1 and Pump 2 respectively, must be by-passed. Removing those valves is not possible as they are integrated into a complex valve block. This problem has been circumvented using two external solenoidoperated valves in parallel to the original secondary valves and by inhibiting the opening of the secondary spools. The new external valves are then controlled in order to achieve the same $\Delta p-$ $Q$ pairs as the original valves for the same joystick signal.

\subsection{The Control Structure}

In the DEXTER system, the pump displacement was controlled using the signal from a pressure sensor positioned on the 'Negacon' line, previously described [4]. This strategy was conceived to mimic the original swashplate hydraulic control system. In this project a Feed-Forward (FF) control strategy similar to a Positive-flow control system has been implemented.

The controller structure is shown in Figure 5. Pilot pressures of each function are imposed by the joystick commands of the operator. Look-up tables are used to convert the pilot pressures $\left(p_{\text {pilots }}\right)$ into displacement demands $\left(V_{d i}\right)$ for each function. The displacement demands of the functions connected to each service are summed $\left(V_{d t o t 1}\right.$ and $\left.V_{d t o t 2}\right)$ and pumplets are allocated to the two services to best satisfy the displacement demands of all functions using a Pumplet allocation algorithm. The Pumplets assigned to each service have limited displacement capacity, so the displacements to each service are saturated $\left(V_{\text {sat } 1}, V_{\text {sat } 2}\right)$. The hydraulic circuit is configured for this Pumplet allocation by acting on the solenoid valves $\left(i_{\text {valves }}\right)$ in the elastic block. The displacement commands ( $V_{\text {tot } 1}$ and $\left.V_{\text {tot2 } 2}\right)$ are limited if the pressure difference between the pump and the active actuator at the highest pressure exceeds a pressure threshold (which is a function of $p_{\text {pilots }}, V_{d_{i}}$ and shaft speed). The pressure limited displacements $\left(V_{\text {lim } 1}, V_{\text {lim } 2}\right)$ are further limited using engine anti-droop and torque limiter logic [4] to respect the available engine torque. The torque limited displacements are converted to final fractions of displacement of each service $\left(F_{d 1}, F_{d 2}\right)$. The maximum displacement of each service is a function of how many pumplets are allocated to each service.

\section{TESTING}

Tests have been conducted to evaluate the effect of the Elastic Pump architecture on fuel consumption on dig-and-dump and grading operations. In particular, for the digging operation, both $90^{\circ}$ Dig-and-Dump and JCMAS air-test [14] cycles were carried out.

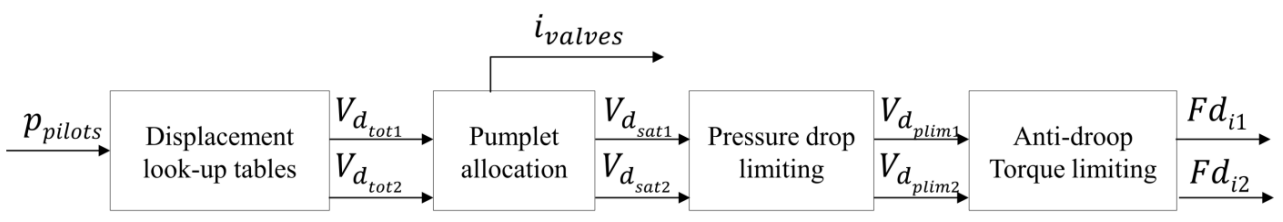

Figure 5: Simplified block-diagram of the control architecture implemented on the excavator using dynamic allocation of the pumps' physical displacement. 


\subsection{Test Cycles}

According to a study of 2015 [15], tracked excavators spend $60 \%$ of their time digging and $15 \%$ grading. Grading is a simple operation in which the soil is flattened using mainly the arm and boom actuators, with the bucket tracing a horizontal line parallel to the ground level. Digging is instead a complex operation that changes over time, depending on the depth of the trench, soil and working conditions. A dig and dump cycle, which is representative of an operation in which material is transferred to a truck, is often used to measure the performance of an excavator, although there are again many parameters that can be varied either intentionally (e.g. angle through which the machine rotates) or unintentionally (e.g. the amount which the bucket is filled). In this project a $90^{\circ}$ dig and dump cycle was used. The JCMAS H020-2007 [14] standard defines a dig-and-dump cycle where the operation is carried out in air only. It is divided into 4 main operations: a grading operation is followed by the tucking of the bucket, boom lift and swing rotation, and terminated with bucket opening. The pressure of each function varies, and when more than one function is supplied by a single flow source throttling is required to control the functions velocities. This cycle was used in this project and will be referred to as 'JCMAS'.

\subsection{Test Set-up}

The tests were conducted at Artemis Intelligent Power (Figure 6) by both employees (internal) and external contractors. The testing ground was soil with some mixed industrial debris (mixed rocks and broken concrete). Any large pieces of debris $\left(>40 \times 30 \times 20 \mathrm{~cm}^{3}\right)$ were removed before testing to ensure consistent test cycles. A $2.5 \mathrm{~m}$ tall metal frame 'hurdle' is used to set a minimum height limit for dig-and-dump and JCMAS Air Loading. The control cabin is used for test engineers to adjust the parameters within the excavator's system controller through remote control features. In particular, the engineers can switch between System Architecture 1 (SA1, DDP with Negative Flow Control) and System Architecture 2 (SA2, Elastic Pump System) while the machine is operating. This remote access can also be used for live fault checking through the Pump controller and DAQ software.
Test data for comparison are recorded within 2 hours to ensure similar ground conditions.

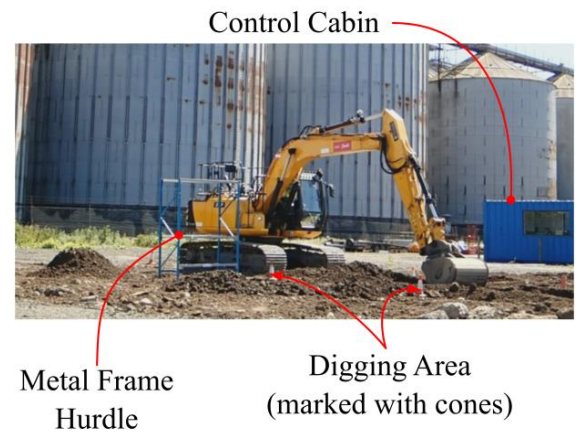

Figure 6: DEXTER excavator during test cycle at Artemis Intelligent Power Ltd.

\subsection{Test Procedure and Validation}

Several tests were performed for each cycle type. During each test, several cycles were repeated. For example, the grading consisted of a circular pattern covering 360 degrees of swing rotation, during which more than 50 full boom/arm extension and retraction were performed. In the case of the JCMAS/digging test, the test was stopped after 20 cycles.

Keeping consistency during the cycle was very hard and the two main factors affected were productivity and end effectors trajectories. In order to select cycles that can be used to perform fair comparisons, a post-processing tool was developed. With this tool, it is possible to evaluate the productivity in terms of useful work/power from experimental data. The useful work for each actuator was defined as

$W=\sum_{i} \int\left(Q_{i n_{i}} \cdot p_{i n_{i}}-Q_{e x h_{i}} \cdot p_{\text {exh }}\right) d t$

Tests exceeding $5 \%$ difference of useful work for the same architecture were discarded.

As will be discussed in the results section, keeping the useful work the same with the change of architecture was not easy for the digging cycle and the grading. However, in the JCMAS cycle, it was possible to keep the same productivity between tests performed with different architectures.

In order to visualize the motion, a 3D kinematic model based on the Denavit-Hartenberg parameters of the machine was developed. 


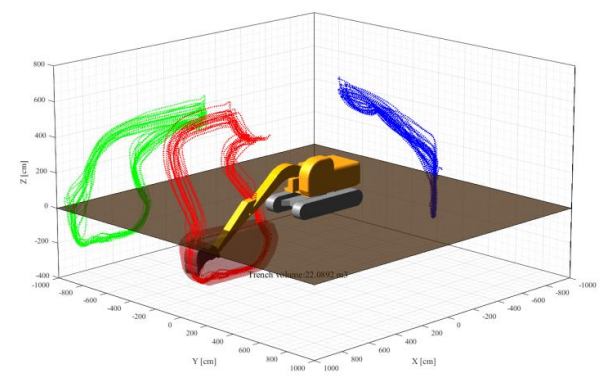

Figure 7: Graphical visualization of a JCMAS air loading cycle. In red, the actual traces, in green and blue the projections on the $\mathrm{z}-\mathrm{x}$ and $z-y$ axis. In red, the volume covered by the bucket is shown.

The model is capable of estimating the volume of the trench, assuming an initially flat surface and non-collapsing walls (Figure 7). The estimation is performed by triangulating the boundary points defined by the bucket and applying a discrete form of the Gauss' theorem. With this tool, the authors were able to perform a qualitative visual inspection of the trajectories in order to spot mistakes of the operators and/or inconsistent cycles. A quantitative approach is also possible; however, the approach is sufficient for the current analysis.

\subsection{Test list and description}

Table 2: Test list and description

\begin{tabular}{lllll}
\hline Operator & $\begin{array}{l}\text { Eng. } \\
\text { Speed }\end{array}$ & $\begin{array}{l}\text { Cycle } \\
\text { Type }\end{array}$ & $\begin{array}{l}\text { N. of } \\
\text { Tests }\end{array}$ & $\begin{array}{l}\text { N. Cycles } \\
\text { Tot. }\end{array}$ \\
\hline External 2 & 1500 & $\begin{array}{l}\text { Dig- } \\
\text { Dump }\end{array}$ & 4 & 100 \\
External 3 & 1500 & $\begin{array}{l}\text { Dig- } \\
\text { Dump } \\
\text { Internal }\end{array}$ & 6 & 72 \\
External 3 & 1500 & JCMAS & 2 & 40 \\
External 2 & 1500 & JCMAS & 4 & 75 \\
External 3 & 1500 & Grading & 4 & 206 \\
External 3 & 1200 & Grading & 1 & 25 \\
\hline
\end{tabular}

All the tests were performed at 1500rpm which is the engine maximum-torque speed except for one grading test performed at $1200 \mathrm{rpm}$. Although several tests were conducted for each cycle type and speed, as shown in Table 2, only a limited amount fulfilled the requirements and have been used for the comparison and presented in the results sections.

\section{RESULTS}

The results are presented in this section for grading and JCMAS air-loading. Unfortunately, the $90^{\circ}$ Dig-and-Dump results were too inconsistent and hence they will not be included. The results show the improvements in terms of fuel consumption, in L/cycle, and productivity, in $\mathrm{kW}$, comparing the System Architecture 1 (SA1Negacon system) with the System Architecture 2 (SA2-Elastic Pump system). Productivity is calculated as

$P=\frac{W}{T}$

Where $\mathrm{W}$ is the useful work defined in equation (7) and T is the cycle time. In this way, the improvement in terms of cycle time can be included. The improvement is calculated as

$\%_{\text {improvement }}=\frac{X_{S A 1}-X_{S A 2}}{X_{S A 1}}$

The test results are also compared with the simulation results. A more thorough analysis is carried on for the results showing significant fuel reduction.

\subsection{JCMAS air-loading}

The Dig-and-Dump test represents the most realistic situation the excavator will incur in the field [15]. The interaction between the machine and the soil represents a significant obstacle for performing a rigorous analysis of this type of cycle so it is common practice to use standardized gravel for consistency, or to test using a JCMAS air-loading cycle where the uncertainties created by the material being moved are eliminated: in this test, the machine structure serves as the load. Figure 8 shows the results obtained comparing measured and simulated data for two tests.

The results summarised in Table 3 show significant improvement in the fuel consumption of up to $16 \%$ with a negligible reduction of productivity of $0.8 \%$ in the first test as well as an improvement of $13.7 \%$ in fuel consumption and $3.3 \%$ in productivity for the second test. It should be emphasised that these results are in addition to any savings achieved by the SA1 system over the standard excavator. 
The simulation and the measurements are closer to each other thanks to very consistent productivity, thus giving confidence in the model output.

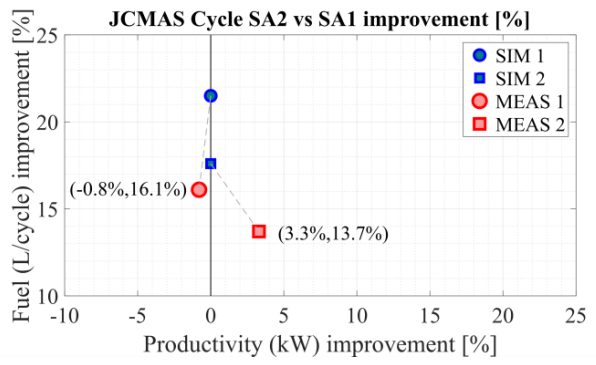

Figure 8: Productivity and Fuel/Cycle improvement for the JCMAS cycle. SIM indicates simulation and MEAS measured data.

Table 3: Summary of the JCMAS tests results

\begin{tabular}{lll}
\hline Test & $\begin{array}{l}\text { Fuel Improvement } \\
{[\mathrm{L} / \text { cycle] }}\end{array}$ & $\begin{array}{l}\text { Productivity } \\
\text { Improvement } \\
{[\mathrm{kW}]}\end{array}$ \\
\hline 1 & $16.1 \%$ & $-0.8 \%$ \\
2 & $13.7 \%$ & $3.3 \%$ \\
\hline
\end{tabular}

\subsection{Grading}

Grading is a low power cycle and it involves only two functions working simultaneously: arm and boom. The ground is scraped trying to keep the penetration depth to a constant level which tests the skills of the operator and the controllability of the machine. Considering the separation of arm and boom pressure, a significant improvement in terms of fuel consumption was expected. In Figure 9 the results obtained comparing measured and simulated data for two tests are shown.

As expected, the results summarised in Table 4 show a great improvement in terms of fuel savings, up to $30.5 \%$ with an associated productivity increase of $15.9 \%$. Even though the results showed a positive improvement for both parameters, it is clear that keeping the productivity consistent between SA1 and SA2 was a difficult goal to reach. This is probably because the control of the machine differs in the SA1 and SA2 cases: in the SA2 case, the velocities of the arm and boom functions do not depend on their relative pressures.

In Test 4 , in order to achieve a similar productivity, the engine speed has been reduced during the SA2 tests until the productivity of the
SA1 case was matched. Similar productivity was reached at $1200 \mathrm{rpm}$. In this condition, $43.8 \%$ of reduction in fuel consumption has been achieved without compromising productivity.

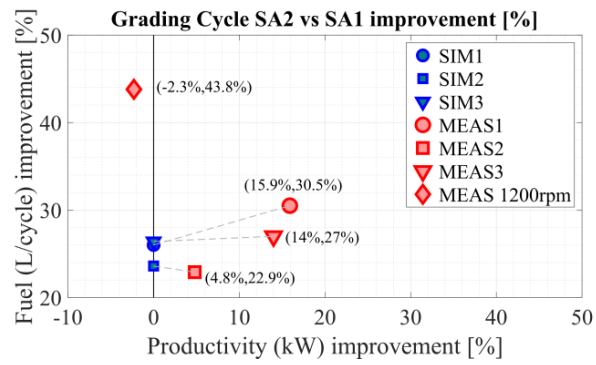

Figure 9: Productivity and Fuel/Cycle improvement for the Grading test cycles. SIM indicates simulation and MEAS measured data.

Table 4: Summary of the Grading tests results

\begin{tabular}{llll}
\hline Test & $\begin{array}{l}\text { Eng. } \\
\text { Speed } \\
{[\mathrm{rpm}]}\end{array}$ & $\begin{array}{l}\text { Fuel } \\
\text { Improvement } \\
{[\mathrm{L} / \text { cycle] }}\end{array}$ & $\begin{array}{l}\text { Productivity } \\
\text { Improvement } \\
{[\mathrm{kW}]}\end{array}$ \\
\hline 1 & 1500 & $30.5 \%$ & $15.9 \%$ \\
2 & 1500 & $22.9 \%$ & $4.8 \%$ \\
3 & 1500 & $27.0 \%$ & $14.0 \%$ \\
4 & 1200 & $43.8 \%$ & $-2.3 \%$ \\
\hline
\end{tabular}

\subsection{Results Analysis}

To understand the reasons for such a decrease in fuel consumption whilst keeping useful power the same (in JCMAS test 2 and Grading test 4), several aspects can be analyzed. Amongst these, the main reasons for a decrease in fuel consumption can be associated to an increase in system efficiency due to a reduction of throttling (delivery) losses, the pump working in a higher efficiency region, and possibly an improved working point on the BSFC map for the engine combined with decreased ancillary loads.

In Table 5 and Table 6 the breakdown of the different sources of losses is shown. It is clear that the biggest portion of the fuel savings has to be attributed to a lower engine power demand caused by a significant reduction in system losses. The decrease of pump losses is marginal, together with the reduction of engine accessory power. 
Table 5: JCMAS Air cycle analysis

\begin{tabular}{llll}
\hline Parameters & $\begin{array}{l}\text { SA1 } \\
(1500 R P M)\end{array}$ & $\begin{array}{l}\text { SA2 } \\
(1500 R P M)\end{array}$ & Variation \\
\hline $\begin{array}{l}\text { Fuel } \\
\text { [L/cycle] }\end{array}$ & 0.066 & 0.057 & $-13.7 \%$ \\
\hline $\begin{array}{l}\text { Avg. Engine } \\
\text { Power [kW] }\end{array}$ & 52.64 & 45.83 & $-11.2 \%$ \\
\hline $\begin{array}{l}\text { System } \\
\text { Useful Power }\end{array}$ & 17.7 & 18.24 & $+3 \%$ \\
[kW] & & & \\
\hline $\begin{array}{l}\text { Avg. System } \\
\text { Losses [kW] }\end{array}$ & 23.4 & 16.32 & $\begin{array}{l}-30 \% \\
(96.3 \% \text { of } \\
\text { total })\end{array}$ \\
\hline $\begin{array}{l}\text { Avg. Pump } \\
\text { Losses [kW] }\end{array}$ & 2.99 & 2.77 & $-7 \%(3 \%$ \\
\hdashline $\begin{array}{l}\text { Engine } \\
\text { Accessory }\end{array}$ & 8.55 & 8.50 & $\begin{array}{l}\text { of total }) \\
\text { Power [kW] }\end{array}$ \\
\hdashline $\begin{array}{l}\text { Engine } \\
\text { BSFC } \\
\text { [g/kWh] }\end{array}$ & 201.8 & 204.3 & of total $)$ \\
\hline $\begin{array}{l}\text { Cycle Time } \\
\text { [s] }\end{array}$ & 18.6 & 18.17 & $+1.2 \%$ \\
\hline
\end{tabular}

Table 6: Grading cycle analysis

\begin{tabular}{|c|c|c|c|}
\hline Parameters & $\begin{array}{l}\text { SA1 } \\
(1500 R P M)\end{array}$ & $\begin{array}{l}\text { SA2 } \\
\text { (1200RPM) }\end{array}$ & Variation \\
\hline $\begin{array}{l}\text { Fuel } \\
{[\text { L/cycle }]}\end{array}$ & 0.039 & 0.0219 & $-43.8 \%$ \\
\hline $\begin{array}{l}\text { Avg. Engine } \\
\text { Power [kW] }\end{array}$ & 59.37 & 33.53 & $-43.5 \%$ \\
\hline $\begin{array}{l}\text { System } \\
\text { Useful } \\
\text { Power }[\mathrm{kW}]\end{array}$ & 16.68 & 16.3 & $-2.3 \%$ \\
\hline $\begin{array}{l}\text { Avg. System } \\
\text { Losses }[\mathrm{kW}]\end{array}$ & 30.87 & 8.31 & $\begin{array}{l}-73 \% \\
(88.6 \% \\
\text { of total) }\end{array}$ \\
\hline $\begin{array}{l}\text { Avg. Pump } \\
\text { Losses }[\mathrm{kW}]\end{array}$ & 3.23 & 1.82 & $\begin{array}{l}-43 \% \\
(5.5 \% \text { of } \\
\text { total })\end{array}$ \\
\hline $\begin{array}{l}\text { Engine } \\
\text { Accessory } \\
\text { Power }[\mathrm{kW}]\end{array}$ & 8.59 & 7.1 & $\begin{array}{l}-17 \% \\
(5.9 \% \text { of } \\
\text { total })\end{array}$ \\
\hline $\begin{array}{l}\text { Engine } \\
\mathrm{BSFC} \\
{[\mathrm{g} / \mathrm{kWh}]}\end{array}$ & 200.2 & 207.1 & $+3.4 \%$ \\
\hline $\begin{array}{l}\text { Cycle Time } \\
{[\mathrm{s}]}\end{array}$ & 9.85 & 9.46 & $-4 \%$ \\
\hline
\end{tabular}

When grading, the power reduction allowed by the DDP enabled a lower engine speed. The fuel consumption is reduced because the total power required from the engine is also reduced. It is important to highlight that BSFC at $1200 \mathrm{rpm}$ is not improved as shown in Table 6 and it is actually slightly worse $(+3.4 \%)$. This shows that, if the system losses would have been kept the same, the fuel consumption would have increased in order to achieve the same amount of work.
During the Dexter project the baseline excavator was tested over a trenching, digging and dig-and-dump cycle [4] but unfortunately not over the JCMAS cycle as is used in this project. However, an estimate of the fuel saving of the SA2 system over the baseline system can be made by combining the average fuel saving over the Dexter test cycles and the SA2 JCMAS result, As shown in Figure 10 the combined saving is more than $30 \%$, which will be verified by direct comparison of the two systems in future.

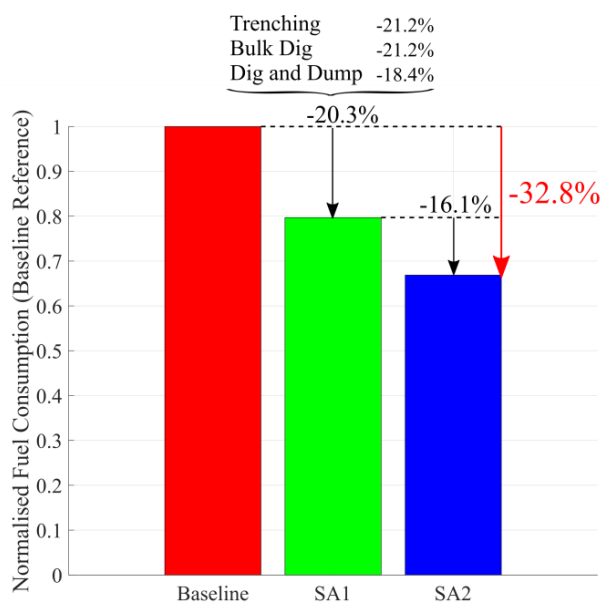

Figure 10: Fuel saving prediction for SA2 system with respect to the baseline machine.

\section{CONCLUSION AND OUTLOOK}

In this work, the conversion of the hydraulic system of a Digital Displacement excavator from a Negacon flow control architecture to a novel dynamic multi-service Digital Displacement ${ }^{\circledR}$ architecture is presented. The new 'Elastic Pump System' exploits the controllability and dynamic service displacement allocation capability of the DDP technology. Field tests showed significant improvements in terms of fuel consumption, in particular, for the JCMAS and grading cycles. The achieved fuel saving was up to $30 \%$ for the same speed with increased productivity and $43 \%$ for reduced speed and the same productivity. This is in addition to the already significant improvement made by the simple pump swap system previously presented [4]. These results show the potential of Digital Displacement ${ }^{\circledR}$ to enable unconventional, yet feasible architectures capable of significant reduction of fuel consumption and increased productivity. 
In the future, additional tests over a wider range of operating conditions will be performed by directly comparing the Elastic Pump System with the standard baseline machine. This will allow a deeper understanding of the potential and limitations of the new architecture enabling a system design optimization in order to move towards the development of a commercially viable solution.

\section{NOMENCLATURE}

$\begin{array}{ll}A & \text { Area } \\ F d & \text { Fraction of Displacement } \\ i & \text { Control Signal } \\ n & \text { Speed } \\ p & \text { Pressure } \\ P & \text { Productivity } \\ Q & \text { Volumetric Flow Rate } \\ s & \text { Service } \\ S A & \text { System Architecture } \\ v & \text { Linear Velocity } \\ V d & \text { Volumetric Displacement } \\ W & \text { Work } \\ X & \text { General Quantity } \\ \omega & \text { Angular Velocity }\end{array}$

\section{REFERENCES}

[1] Oak Ridge National Laboratory (2012) Estimating the Impact (Energy, Emissions and Economics) of the US Fluid Power Industry.

[2] Heybroek K (2017) On Energy Efficient Mobile Hydraulic Systems, Phd Thesis, Linköping University.

[3] Lynch L, Zigler B (2017) National Renewable Energy Laboratory report: "Estimating energy consumption of mobile fluid power in the United States", NREL.

[4] Green M, Macpherson J, Caldwell N, and Rampen WHS (2018) DEXTER: The Application of a Digital Displacement ${ }^{\circledR}$ Pump to a 16 Tonne Excavator. In BATH/ASME 2018 Symposium on Fluid Power and Motion Control. American Society of Mechanical Engineers Digital Collection.

[5] Budden J, Williamson C, Danfoss Digital Displacement Excavator: Test Results and Analysis, ASME/BATH 2019 Symposium on Fluid Power and Motion Control. American Society of Mechanical Engineers Digital Collection.
[6] Rampen W, Caldwell N, Stein U, Joly P, and Fielding M, Fluid Power Distribution and Control System, International Patent Application PCT/GB2007/002747.

[7] Zimmerman J D (2012) Toward optimal multiactuator displacement controlled mobile hydraulic systems (Doctoral dissertation, Purdue University).

[8] Weber J et al. (2016) Novel System Architectures by Individual Drives. The 10th International Fluid Power Conference.

[9] Minav T, Heikkinen J, Pietola M, (2017) "Direct driven hydraulic drive for new powertrain topologies for non-road mobile machinery", Electric Power Systems Research.

[10] Vukovic D (2016) STEAM-a hydraulic hybrid architecture for excavators.

[11] Caldwell N, Review of early work on Digital Displacement Hydrostatic Transmission Systems, In BATH/ASME 2018 Symposium on Fluid Power and Motion Control. American Society of Mechanical Engineers.

[12] Ivantysynova M (2001) Energy losses of modern displacement machines-a new approach of modelling. The Seventh Scandinavian International Conference on Fluid Power, Linköping.

[13] Caldwell N J (2007). Digital displacement hydrostatic transmission systems. Phd Thesis, The University of Edinburgh.

[14] JCMAS H020:2007 (2007) Earth-moving machinery - Fuel consumption on hydraulic excavator - Test procedure.

[15] Fecke M (2015) Standardisierung definierter Lastzyklen und Messmethoden zur Energieverbrauchsermittlung von Baumaschinen. Proceedings of the 5 th Fachtgaung Baumaschinentechnik, Dresden, Germany, 17-19.

Digital Displacement ${ }^{\circledR}$ is a registered trademark of Artemis Intelligent Power Ltd. 